\title{
Association between blood lead levels and environmental exposure among Saudi schoolchildren in certain districts of Al-Madinah
}

This article was published in the following Dove Press journal:

International Journal of General Medicine

16 April 2012

Number of times this article has been viewed

\author{
Mohammed Adnan Zolaly' \\ Manal Ibrahim Hanafi ${ }^{2,3}$ \\ Nashaat Shawky ${ }^{4}$ \\ Khalid el-Harbi' \\ Ahmed M Mohamadin ${ }^{5,6}$ \\ 'Pediatric Department, ${ }^{2}$ Family and \\ Community Medicine Department, \\ Medical College, Taibah University, \\ Al-Madinah Al-Munawwarah, Saudi \\ Arabia; ${ }^{3}$ Community Medicine \\ Department, Faculty of Medicine, \\ Alexandria University, Alexandria, \\ Egypt; ${ }^{4}$ Ophthalmology Department, \\ Medical College, ${ }^{5}$ Chemistry for \\ Health Sciences Department, \\ Deanery of Academic Services, \\ Taibah University, Al-Madinah \\ Al-Munawwarah, Saudi Arabia; \\ ${ }^{6}$ Biochemistry Department, Faculty \\ of Pharmacy, Al-Azhar University, \\ Cairo, Egypt
}

Introduction: Both occupational and environmental exposures to lead remain a serious problem in many developing and industrializing countries. When humans are exposed to high levels of lead, there is damage to almost all organs and organ systems (most importantly, the central nervous system, kidneys, and blood), which often culminates in death.

Objective: To estimate the prevalence of blood lead levels (BLLs) and to identify the sources of environmental exposure and potential risk factors for elevated BLLs among Saudi schoolchildren.

Methods: A cross-sectional survey was conducted from March to May 2010. The study population included 557 Saudi school students of both sexes. A multistage random sampling technique was used. Information about socioeconomic status, house and school construction, and parents' education and employment was collected using questionnaires. Lead was analyzed in a blood sample using an atomic absorption technique and hemoglobin was measured using a Sysmex hematological analyzer.

Results: The mean BLL was $4.94 \pm 3.38 \mu \mathrm{g} / \mathrm{dL}$ (range $0.45-26.3 \mu \mathrm{g} / \mathrm{dL}$ ). A total of $19 \%$ had BLLs $<1.0 \mu \mathrm{g} / \mathrm{dL}, 16 \%$ had BLLs $<2.5 \mu \mathrm{g} / \mathrm{dL}, 15 \%$ had BLLs $<5.0 \mu \mathrm{g} / \mathrm{dL}, 20 \%$ had BLLs $<7.5 \mu \mathrm{g} / \mathrm{dL}, 25 \%$ had BLLs $<10.0 \mu \mathrm{g} / \mathrm{dL}$, and about $6 \%$ had BLLs $>10.0 \mu \mathrm{g} / \mathrm{dL}$. Analysis of odds by controlling all risk factors (adjusted odds ratio [OR]) that affect BLLs ( $\geq 10 \mu \mathrm{g} / \mathrm{dL}$ ) indicated that using cosmetics $(\mathrm{OR}=18.5$, confidence interval $[\mathrm{CI}]=14.4-19.8)$, putting colored toys in mouth $(\mathrm{OR}=15.7, \mathrm{CI}=3.6-16.2)$, eating canned food $(\mathrm{OR}=9.8, \mathrm{CI}=7.0-10.1)$, and using newspaper during food preparation $(\mathrm{OR}=7.6, \mathrm{CI}=6.3-8.2)$ are risk factors. There were significant correlations between BLLs and family habits $(\mathrm{r}=0.225, P=0.000)$, personal habits ( $\mathrm{r}=0.321, P=0.000)$, eating habits $(\mathrm{r}=0.128, P=0.002)$ and school building characteristics $(\mathrm{r}=0.469, P=0.000)$. There was a significant correlation between BLLs and anemia in age group $6<12$ years $(P=0.000)$ and age group 12 to less than 18 years, among males $(P=0.000)$ and females $(P=0.041)$.

Conclusion: The BLLs of children are affected by multiple factors. Female students have higher BLLs and lower hemoglobin concentration than males. The possible sources of lead exposure were use of toothpaste, use of kohl, putting colored toys in the mouth, use of both canned food and canned juice, use of lip gloss in females, and different methods of handling newspaper while preparing food.

Keywords: blood, lead, exposure, cosmetics, schoolchildren, anemia

Correspondence: Ahmed M Mohamadin Chemistry for Health Sciences, Deanery of Academic Services, Taibah University, Al-Madinah, KSA Madinah 4I48I,

PO Box 3513, Saudi Arabia

Tel +966508468I42

Fax +966048470926

Email amohamadin@yahoo.com

\section{Introduction}

Lead is a metal that has been associated with human activities for the past 6000 years. That lead is an environmental toxin is an ancient observation. Despite increased attention, lead poisoning is still a serious problem. Lead is a ubiquitous environmental 
and industrial pollutant that has been detected in every facet of environmental and biological systems. ${ }^{1,2}$ Lead is a major industrial byproduct and can be found in water pipes, insecticides, linings of equipment where corrosion resistance and pliability are required, petroleum refining, construction, bullets, and X-ray and atomic-radiation protection equipment. The manipulation of lead for these uses has caused lead contamination of air, dust, and soil. Lead has been known to cause mental retardation and learning disorders. ${ }^{3,4}$ Further sources of lead exposure include automobile emissions from use of leaded gasoline, industrial emissions, cottage industries (eg, battery recycling), lead-soldered cans and water pipes, lead-glazed ceramics, and traditional medicines. ${ }^{5,6}$ Lead exposure may occur in the home (eg, paint, dust, and soil), workplace, other environments (eg, parents' occupation and hobbies), or from the use of folk remedies containing lead. ${ }^{7,8}$ Further, lead exposure may occur through ingestion of flaking lead paint and inhalation of dust and soil contaminated with such paint (Table 1). ${ }^{9}$

Lead poisoning in adults occurs more frequently from exposure in the workplace and primarily involves the central nervous system (CNS). Children are more susceptible to lead exposure than adults because they participate in age-appropriate behaviors and activities that result in greater exposure, causing them to absorb more lead than adults and their overall development is also affected. ${ }^{10}$ Children absorb $40 \%-50 \%$ of dietary lead and retain $2 \%-25 \%$, whereas adults absorb 5\%-10\% and retain little. ${ }^{11}$ Furthermore, children's digestive systems absorb lead more readily than an adult's system, and their premature and still-developing CNS is more vulnerable to lead toxicity than a mature CNS. ${ }^{1,12}$ Lead is a pervasive environmental toxin that affects virtually every system in the body. Evidence of harmful effects in various organs has been found in children whose BLLs exceed $10 \mu \mathrm{g} / \mathrm{dL} .{ }^{13}$

In 2000, an estimated 120 million people around the world had blood lead concentrations of between 5 and $10 \mu \mathrm{g} / \mathrm{dL}$, and about the same number had concentrations of $>10 \mu \mathrm{g} / \mathrm{dL}$. Forty percent of all children had blood lead concentrations of $>5 \mu \mathrm{g} / \mathrm{dL}$, and half of these had blood lead concentrations of $>10 \mu \mathrm{g} / \mathrm{dL}$; of these children, $97 \%$ were living in developing countries. ${ }^{14}$ Estimates published recently suggest that the theoretical minimum risk of health effects may occur at blood lead concentrations as low as $0-1 \mu \mathrm{g} / \mathrm{dL} .^{14,15}$ Blood lead concentrations are indicative of recent lead exposure (within the preceding few weeks) rather than of cumulative long-term exposure. However, exposure to lead varies relatively little over the period
Table I Possible sources of lead ${ }^{6-10}$

\begin{tabular}{|c|c|}
\hline Occupational & Environmental/Other \\
\hline Painters & Lead-based paint (pre-1978) \\
\hline Home remodelers/renovators & Soil/Dust near lead industries, \\
\hline Construction/Demolition workers & roadways, \\
\hline Bridge maintenance/repair & Plumbing and solder \\
\hline Auto body repairers/painters & Cosmetics and hair dye \\
\hline Battery manufacturers/recyclers & Imported vinyl mini-blinds \\
\hline Radiator repairers/manufacturing & Imported ceramic tiles for the \\
\hline Furniture refinishers & kitchen/bathroom \\
\hline Plumbers, pipe fitters & Building materials \\
\hline Roofers & Gutters, flashings, tiles, window \\
\hline Lead miners, smelters, and refiners & glazing \\
\hline Glass, copper and brass manufacturers & Ceramic ware/glazed pottery \\
\hline Boat builders/painters/repair/ & Porcelain bathtubs \\
\hline maintenance & Leaded glass/pewter \\
\hline Ceramics making/Glaze mixing & Leaded gasoline \\
\hline Printers (ink) & (race, collector cars) \\
\hline Plastic and rubber manufacturers & Soldered seams-imported \\
\hline Police officers & canned food \\
\hline Firing range instructors & Soldered copper pipes \\
\hline Steel welders or cutters & Submersible pumps in wells \\
\hline Jewelry making & Brass plumbing fixtures \\
\hline Gas station attendants & Bronze, pewter, leaded crystal \\
\hline Aircraft repair & Electronics manufacturers \\
\hline X-ray shielding/Film radiology & Pesticides \\
\hline Hobbies and related activities & Storage batteries \\
\hline Home remodeling/renovation & Plastic insulation on electrical \\
\hline Car or boat repair & wiring and old telephone wiring \\
\hline Glazing/Making pottery & Ingested sources \\
\hline $\begin{array}{l}\text { Reloading/Target shooting at firing } \\
\text { ranges }\end{array}$ & $\begin{array}{l}\text { Traditional/Home remedies } \\
\text { (eg, azarcon, kohl, ayurvedic) }\end{array}$ \\
\hline Furniture refinishing & Imported candy and candy \\
\hline Making/Handling lead shot and fishing & wrappers \\
\hline weights/sinkers & Supplements (eg, calcium) \\
\hline Using lead soldering/welding & \\
\hline Oil painting (artistic) & \\
\hline Using pastel art pencils & \\
\hline Making stained glass & \\
\hline Jewelry making & \\
\hline Using/Making diving and exercise & \\
\hline weights & \\
\hline Repairing old painted wooden & \\
\hline
\end{tabular}

Note: Lead-based paint and lead contaminated dust are the most common sources of lead exposure for children.

of a year this measure can also be a sign of longer-term exposure. $^{16}$

Workers are also at particular risk in battery manufacturing, demolition work, welding, pottery and ceramic-ware production (often a home-based occupation involving women and children), small businesses repairing automobile radiators, and artisan production of jewelry and decorative items. The last category is of particular concern since the work is predominantly carried out at home or in unregulated workshops, often by women and children. Although adults are mainly 
involved, in many countries (especially those with developing industries), particularly in small home-based enterprises, there is little distinction between home and workplace, and children are consequently exposed to lead. Because of the transfer of lead to the fetus in utero and the introduction of lead into people's homes on clothing, through which young children are exposed, problems of occupational exposure become community problems. ${ }^{7,17}$

Because of rapid industrialization and the persistence of lead in the environment, exposure is likely to remain a significant public health problem in most developing countries for many years; this includes in Al-Madinah, Saudi Arabia. To prepare an action plan, one must first know the prevalence of lead exposure and its sources among the population most affected; namely, children.

The current study was conducted to estimate the prevalence of blood lead levels (BLLs) and to identify the sources of environmental exposure and potential risk factors for elevated BLLs among Saudi schoolchildren.

\section{Subjects and methods}

A cross-sectional survey was conducted from March to May 2010. The study population included Saudi school students (of elementary, intermediate, and secondary schools) of both sexes. The total number of students to be selected was estimated using the following formula: $\mathrm{n}=\left(\mathrm{Z}^{2} \times P \times \mathrm{q}\right) / \mathrm{D}^{2}{ }^{18}$ Since the actual prevalence of elevated BLL is $20 \%$, the probability of its occurrence was estimated to be $P=0.20$. Accordingly, the probability of nonoccurrence will be $\mathrm{q}=(1-P)=0.80$. A value of 0.03 was chosen as the acceptable limit of precision (D) at 95\% confidence intervals (CIs) where $(Z=1.96)$. Based on these assumptions, the sample size was estimated at 682.95 children. For ease of calculation and analysis, 685 was chosen as the minimum sample size. The proposal was approved by the human subjects committees at the Taibah University, Ministry of Health, and Ministry of Education, Kingdom of Saudi Arabia.

A multistage sampling technique was used. First, a review of the records of all schools (elementary, intermediate, and secondary schools for boys and girls) was undertaken, and the schools were listed by grade and sex. Then, one school from each grade and each sex was randomly selected. After allocation of the selected schools, classes were enlisted, and then students were simply selected randomly.

\section{Questionnaire}

An anonymous self-administered questionnaire was distributed to the students at their schools to take home for their parents to fill in. The questionnaire was prepared in Arabic. Some questionnaires had to be administered by trained interviewers because some parents were not able to complete them without assistance. The purpose, procedure, risks, and benefits of the study were explained to the respondents and verbal and written informed consent was obtained. The survey tool was pre-tested on a random sample of 20 participants to ensure practicability, validity, and interpretation of responses. The reliability of the questionnaire was assessed using Cronbach's alpha (0.812). The questionnaire included queries on family size; socioeconomic status, including questions on number of possessions, house condition (year of construction, presence of lead pipes, last time the house was painted, number of rooms and bedrooms in the house, whether the family owned or rented the house), parents' education, and employment status; characteristics of school construction; pregnancy outcomes (birth weight and gestational age); breastfeeding history (duration of breastfeeding and child's age at the time liquids other than breast milk and solid foods were introduced); and the child's health (history of anemia, use of iron-fortified formula or cereals, whether the child uses a pacifier or puts fingers/toys in his/her mouth) and general diet (how many times in the last week did the child consume any fruits, vegetables, meat, eggs, legumes, and dairy products). The "family possessions" variable was constructed by summing the presence in the household of one or more of the following items: TV, video player, DVD player, computer, video games, radio, sound equipment, refrigerator, washer, house phone, cellular phone, or car.

BLLs were analyzed by Zeeman background-corrected flameless graphite furnace atomic absorption (model Z-8100; Hitachi, Tokyo, Japan). The limit of detection for the blood lead concentrations was $1.0 \mu \mathrm{g} / \mathrm{dL} .{ }^{19}$ Hemoglobin was assessed by a Sysmex XE-2100 Automated Hematology Analyzer (Sysmex, Kobe, Japan) with the appropriate calibrator, reagent kits, and quality control processes. ${ }^{20}$

The mean percent score was calculated (using the formula: total score/maximum possible score $\times 100$ ) for the following: household exposure (household construction characteristics; see next paragraph), school exposure (school construction characteristics; see below), family, personal, and eating habits.

Hierarchical cluster analysis was used to summate the following: housing construction characteristics (including presence of a workshop or factory near house, width of street, type of house, paint, ground type, water source, and presence of water tanks), school construction characteristics 
Table 2 Demographics of the students in the blood lead level (BLL) survey by school grade, sex, age, and BLL

\begin{tabular}{|c|c|c|c|c|c|c|c|c|}
\hline \multirow[t]{3}{*}{ Parameters } & \multicolumn{6}{|c|}{ School level } & \multicolumn{2}{|l|}{ Total } \\
\hline & \multicolumn{2}{|c|}{ Elementary ${ }^{\mathbf{a}}$} & \multicolumn{2}{|c|}{ Intermediate ${ }^{\mathrm{b}}$} & \multicolumn{2}{|c|}{ Secondary ${ }^{c}$} & \multirow[b]{2}{*}{$\mathbf{N}=557$} & \multirow[b]{2}{*}{$\%$} \\
\hline & $\mathbf{N}=204$ & $\%$ & $N=188$ & $\%$ & $N=165$ & $\%$ & & \\
\hline \multicolumn{9}{|l|}{ Sex } \\
\hline Males & 109 & 53.4 & 102 & 54.3 & 85 & 51.5 & 296 & 53.0 \\
\hline Females & 95 & 46.6 & 86 & 45.7 & 80 & 48.5 & 261 & 47.0 \\
\hline \multicolumn{9}{|l|}{ Age in years } \\
\hline $6<12$ & 204 & 100.0 & - & - & - & - & 204 & 36.6 \\
\hline $12<15$ & - & - & 188 & 100.0 & - & - & 188 & 33.7 \\
\hline $15<18$ & - & - & - & - & 165 & 100.0 & 165 & 29.6 \\
\hline \multicolumn{9}{|l|}{ BLL $(\mu / d L)$} \\
\hline$<\mathrm{I} \mu / \mathrm{dL}$ & 39 & 19.1 & 38 & 20.2 & 28 & 17.0 & 105 & 18.9 \\
\hline $\mathrm{I}<2.5 \mu / \mathrm{dL}$ & 28 & 13.7 & 30 & 16.0 & 32 & 19.4 & 90 & 16.2 \\
\hline $2.5<5 \mu / d L$ & 25 & 12.3 & 26 & 13.8 & 30 & 18.2 & 81 & 14.5 \\
\hline $5<7.5 \mu / d \mathrm{~L}$ & 47 & 23.0 & 40 & 21.3 & 23 & 13.9 & 110 & 19.7 \\
\hline $7.5<10 \mu / \mathrm{dL}$ & 56 & 27.5 & 43 & 22.9 & 41 & 24.8 & 140 & 25.1 \\
\hline$\geq 10 \mu / \mathrm{dL}$ & 9 & 4.4 & II & 5.8 & 11 & 6.7 & 31 & 5.6 \\
\hline
\end{tabular}

Notes: Values are expressed as means \pm standard deviation or percentage scores. The sample size of each school level was calculated according to the number of students in each school grade level. aElementary: school grade levels from grade I to grade 6. 'lntermediate: school grade levels from grade 7 to grade 9 . 'Secondary: school grade levels from grade 10 to grade 12 .

Abbreviation: BLL, blood lead level.

(including presence of workshop or factory near school, width of street, paint, floor, and ground type), family habits (including bakhoor [from the Arabic language; used to describe most incense resins or fragranced wood chips] use, smoking, utensils used in food storage and preparation), personal (use of kohl [an ancient eye cosmetic], cosmetics, lip gloss in females, playing with newspapers, putting colored toys in mouth; and up to the end of elementary school, using colored pencils), and eating habits (including canned food; canned juice; type of utensils used for food preparation and storage; use of newspapers in food preparation, storage, wrapping, and as table mats). After cluster analysis, correlation of some parameters with BLL $<10 \mu \mathrm{g} / \mathrm{dL}$ and BLL $>10 \mu \mathrm{g} / \mathrm{dL}$ was undertaken.

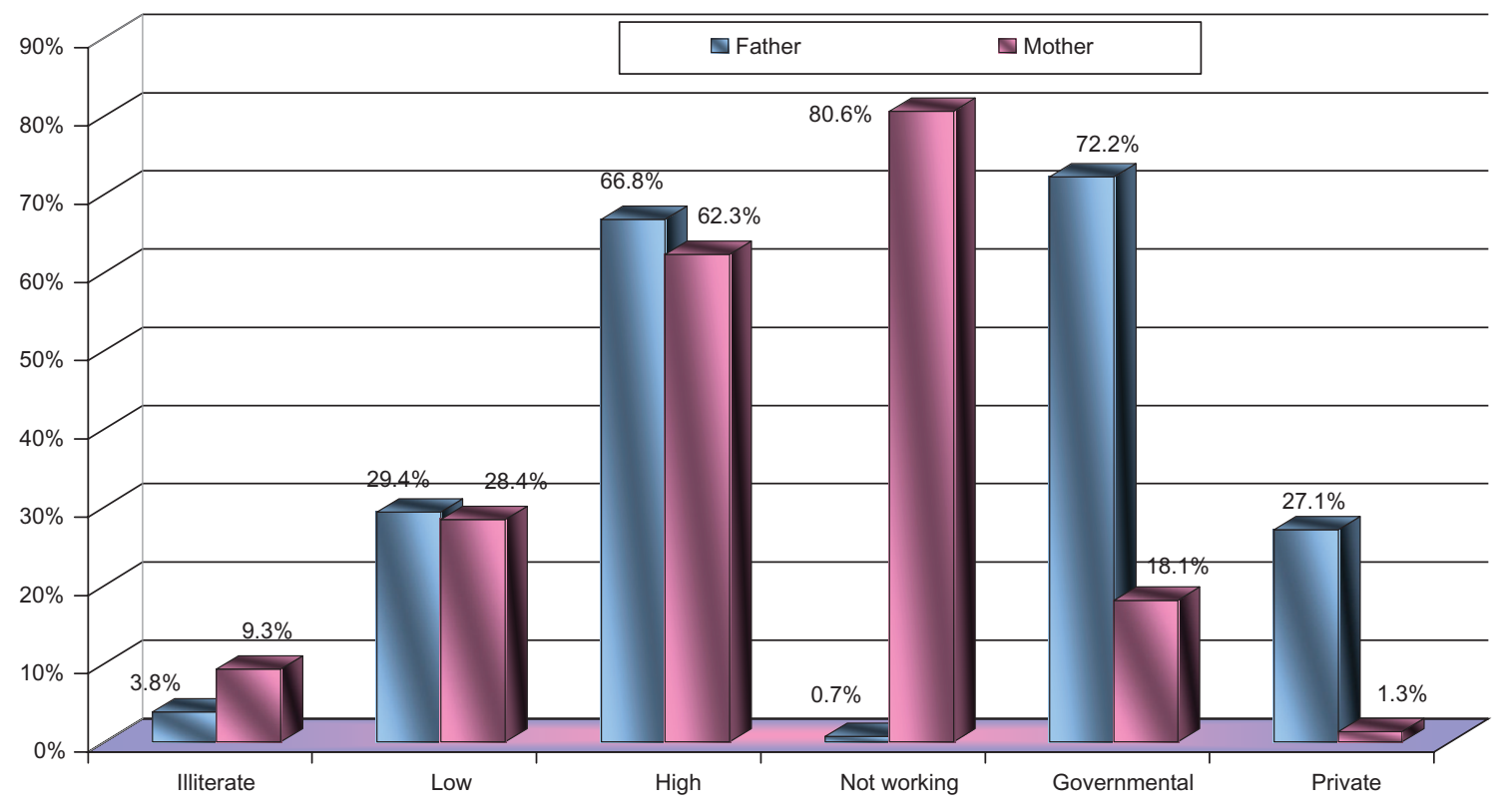

Figure I Education and work status of father and mother.

Notes: Values are expressed as means \pm standard deviation or percentage scores. Odds ratios with $95 \% \mathrm{Cl}$ are reported for all variables entered into multivariate analysis $(P<0.05)$. 


\section{Statistical analysis}

Data were entered and analyzed using SPSS (v 13.0; IBM Corp, Armonk, NY). Data gathered from the cross sectional survey were analyzed using the case control approach. The chi-square test was used for comparisons of nonparametric data. Student's $t$-test was used for comparisons of parametric data. Spearman's rank correlation was used to study correlations. Odds ratio (OR) and the corresponding 95\% CI were computed for high BLL. Multiple linear regressions were performed to predict possible causes for increase in BLL.

Table 3 Association between blood lead level and family and personal habits

\begin{tabular}{|c|c|c|c|c|c|c|}
\hline & \multicolumn{2}{|c|}{$<10 \mu \mathrm{g} / \mathrm{dL}, \mathrm{n}=533$} & \multicolumn{2}{|c|}{$\geq 10 \mu \mathrm{g} / \mathrm{dL}, \mathrm{n}=24$} & \multirow[t]{2}{*}{ OR $^{*}$} & \multirow[t]{2}{*}{$\mathrm{Cl}$ at $95 \%$} \\
\hline & $\mathbf{N}$ & $\%$ & $\mathbf{N}$ & $\%$ & & \\
\hline \multicolumn{7}{|c|}{ Use of bakhoor ${ }^{a}$} \\
\hline No & 100 & 18.8 & I & 4.2 & 5.3 & $5.0-6.1$ \\
\hline Yes & 433 & 81.2 & 23 & 95.8 & & \\
\hline \multicolumn{7}{|c|}{ Passive smoking } \\
\hline No & 313 & 58.7 & 9 & 37.5 & 2.4 & I.2-5.5 \\
\hline Yes & 220 & 41.3 & 15 & 62.5 & & \\
\hline \multicolumn{7}{|c|}{ Putting colored toys in the mouth } \\
\hline No & 313 & 58.7 & 2 & 8.3 & 15.7 & $3.6-16.2$ \\
\hline Yes & 220 & 41.3 & 22 & 91.7 & & \\
\hline \multicolumn{7}{|c|}{ Using colored pencils } \\
\hline No & 117 & 22.0 & 1 & 4.2 & 6.5 & $4.8-8.7$ \\
\hline Yes & 416 & 78.0 & 23 & 95.8 & & \\
\hline \multicolumn{7}{|c|}{ Some food habits } \\
\hline \multicolumn{7}{|c|}{ Eating canned food } \\
\hline No & 159 & 29.8 & I & 4.2 & 9.8 & $7.0-10.1$ \\
\hline Yes & 374 & 70.2 & 23 & 95.8 & & \\
\hline \multicolumn{7}{|c|}{ Drinking canned juice } \\
\hline No & 88 & 16.5 & 2 & 8.4 & 2.2 & $1.4-3.8$ \\
\hline Yes & 445 & 83.5 & 22 & 91.6 & & \\
\hline \multicolumn{7}{|c|}{ For females only $(n=262)$} \\
\hline \multicolumn{7}{|c|}{ Cosmetic use } \\
\hline No & 127 & 52.0 & 1 & 5.6 & 18.5 & $14.4-19.8$ \\
\hline Yes & 117 & 48.0 & 17 & 94.4 & & \\
\hline \multicolumn{7}{|c|}{ Use of kohlb } \\
\hline No & 64 & 26.2 & 1 & 5.6 & 6.0 & $5.7-8.3$ \\
\hline Yes & 180 & 73.8 & 17 & 94.4 & & \\
\hline \multicolumn{7}{|c|}{ Use of lip gloss } \\
\hline No & 68 & 27.9 & I & 5.6 & & \\
\hline Yes & 176 & 72.1 & 17 & 94.4 & 6.6 & 6.1-7.4 \\
\hline \multicolumn{7}{|c|}{ Use of toothpaste } \\
\hline No & 121 & 22.7 & 1 & 4.2 & 6.8 & $5.8-7.8$ \\
\hline Yes & 412 & 77.3 & 23 & 95.8 & & \\
\hline \multicolumn{7}{|c|}{ Use of newspapers in: } \\
\hline \multicolumn{7}{|c|}{ Playing } \\
\hline No & 473 & 88.7 & 21 & 87.5 & I.I & $1.1-3.9$ \\
\hline Yes & 60 & 11.3 & 3 & 12.5 & & \\
\hline \multicolumn{7}{|c|}{ During food preparation } \\
\hline No & 356 & 66.8 & 5 & 20.8 & 7.6 & $6.3-8.2$ \\
\hline Yes & 177 & 33.2 & 19 & 79.2 & & \\
\hline \multicolumn{7}{|c|}{ Wrapping and preserving food } \\
\hline No & 416 & 78.0 & 10 & 41.7 & 5.0 & $2.2-3.5$ \\
\hline Yes & 117 & 22.0 & 14 & 58.3 & & \\
\hline \multicolumn{7}{|c|}{ As table mats } \\
\hline No & 333 & 62.5 & 5 & 20.8 & 6.3 & $5.2-7.6$ \\
\hline Yes & 200 & 37.5 & 19 & 79.2 & & \\
\hline
\end{tabular}

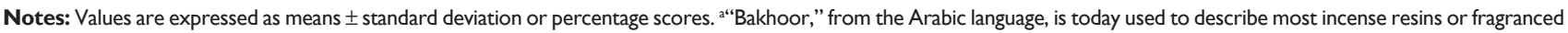
wood chips. ${ }^{b} \mathrm{Kohl}$ is an ancient eye cosmetic. ${ }^{*}$ Odds ratios $(\mathrm{OR}]$ with $95 \%$ confidence interval $(\mathrm{Cl})$ are reported for all variables entered into multivariate analysis $(P<0.05)$. 


\section{Results}

A total of 557 students participated in the survey, corresponding to approximately $81.3 \%$ of the total number of students (685) eligible to participate from the 18 schools. Sex and age distributions varied considerably across schools because nine girls' schools constituted $47 \%$ of the recruited students with a mean age $11.6 \pm 2.63$ years, and nine boys' schools constituted $53 \%$ of the recruited students with a mean age $12.5 \pm 3.5$ years (Table 2). The mean BLL was $4.94 \pm 3.38 \mu \mathrm{g} / \mathrm{dL}$, with a significant difference between male and female BLLs ( $\mathrm{r}=0.406, P=0.000)$. The distributions of BLLs across six blood-lead categories are presented in Table 2 . In the three school study levels (elementary, intermediate, and secondary), $19 \%$ of children had BLLs $<1.0 \mu \mathrm{g} / \mathrm{dL}, 16.2 \%$ had BLLs from 1.0 to $2.499 \mu \mathrm{g} / \mathrm{dL}, 14.5 \%$ had BLLs from 2.5 to $4.99 \mu \mathrm{g} / \mathrm{dL}, 19.7 \%$ had BLLs from 5.0 to $7.49 \mu \mathrm{g} / \mathrm{dL}, 25 \%$ had BLLs from 7.5 to $9.99 \mu \mathrm{g} / \mathrm{dL}$, and about $5.6 \%$ had BLLs of $\geq 10 \mu \mathrm{g} / \mathrm{dL}$ (Table 2).

Geometric mean BLLs were significantly associated with family size and education level of the parent guardian. Figure 1 shows that $66.8 \%$ of fathers and $62.3 \%$ of mothers had a high level of education; meanwhile $80.6 \%$ of mothers were housewives. None of the fathers of the students who had BLLs of $\geq 10 \mu \mathrm{g} / \mathrm{dL}$ had occupational exposure to lead. The mean family size was $7.4 \pm 2.12$ and mean general crowding index was $1.6 \pm 0.59$. There was a significant relationship between mean family size and, general crowding index and BLL $(\mathrm{r}=0.086, P=0.042$ and $\mathrm{r}=0.112$, $P=0.008$, respectively).

Table 3 compares the general data of the surveyed individuals grouped according to BLLs. Study groups had significantly differentiated family and personal habits. Table 3 shows the association between BLLs and family and personal habits, where the highest risk values were associated with the use of cosmetics $(\mathrm{OR}=18.5, \mathrm{CI}=14.4-19.8)$, putting colored toys in mouth $(\mathrm{OR}=15.7, \mathrm{CI}=3.6-16.2)$, eating canned food $(\mathrm{OR}=9.8, \mathrm{CI}=7.0-10.1)$, and using newspaper during food preparation $(\mathrm{OR}=7.6, \mathrm{CI}=6.3-8.2)$. Using cluster analysis, Table 4 illustrates a significant correlation between BLLs and family habits $(\mathrm{r}=0.225, P=0.000)$, personal habits $(\mathrm{r}=0.321$, $P=0.000)$, eating habits $(\mathrm{r}=0.128, P=0.002)$ and school construction characteristics $(\mathrm{r}=0.469, P=0.000)$.

There was a significant relationship between BLLs and family habits $(P=0.000, \mathrm{OR}=8.6, \mathrm{CI}=4.1-11.3)$, personal habits $(P=0.000, \mathrm{OR}=5.2, \mathrm{CI}=2.1-8.6)$, eating habits $(P=0.000, \mathrm{OR}=22.3, \mathrm{CI}=20.4-26.7)$, and mean percent score of possible sources of lead exposure $(P=0.000$, $\mathrm{OR}=35.5, \mathrm{CI}=34.1-40.5$ ) (Table 5, Figure 2).

Regarding the relationship between BLLs and hemoglobin level, Table 6 shows that there was significant correlation in age group 6-11 years $(P=0.000)$ and age group $12-18$ years, among males $(P=0.000)$ and females $(P=0.041)$.

It was found that the predictors for high BLL (Table 7) were the use of toothpaste $(P=0.000)$, kohl $(P=0.000)$, putting colored toys in the mouth $(P=0.000)$, canned food and canned juice ( $P=0.008$ and 0.018 , respectively), use of lip gloss in females $(P=0.000)$, and different ways of handling newspapers while preparing food.

\section{Discussion}

Both occupational and environmental exposures to lead remain a serious problem in many developing and industrializing countries, as well as in some developed countries. ${ }^{1}$ Lead is a potent poison that can affect individuals at any age. Children with developing bodies are especially vulnerable because their rapidly developing nervous systems are particularly sensitive to the effects of lead. ${ }^{1,10}$ Lower age as a risk factor for elevated BLLs among children aged 6-18 years has not been investigated in many countries. The data presented in Table 2 show an apparent increase in BLLs in the young compared with older people. However, these results are inconsistent with reports from the USA and Australia, where BLLs are highest in 1- to 2-year-old children and decline later. ${ }^{21}$ In contrast, a study from Russia reported little variation in lead levels by age. ${ }^{22}$

In the year 2000, an estimated 120 million people around the world had blood lead concentrations of between 5 and

Table 4 Correlation between blood lead level and some studied characters (cluster analysis)

\begin{tabular}{|c|c|c|c|c|c|c|}
\hline \multirow[t]{2}{*}{ Parameters } & \multicolumn{2}{|c|}{$<10 \mu \mathrm{g} / \mathrm{dL}$} & \multicolumn{2}{|c|}{$\geq 10 \mu \mathrm{g} / \mathrm{dL}$} & \multicolumn{2}{|c|}{ All studied groups } \\
\hline & $\mathbf{R}^{\mathbf{a}}$ & Significance & $\mathbf{R}^{\mathbf{a}}$ & Significance & $\mathbf{R}^{\mathbf{a}}$ & Significance \\
\hline Housing construction characteristics & 0.023 & 0.603 & 0.024 & 0.580 & 0.046 & 0.282 \\
\hline Family habits & $0.278 * *$ & 0.000 & 0.051 & 0.811 & $0.255^{* *}$ & 0.000 \\
\hline Personal habits & $0.208 * *$ & 0.000 & 0.060 & 0.781 & $0.321 * *$ & 0.000 \\
\hline Eating habits & 0.078 & 0.073 & 0.248 & 0.243 & $0.128 * *$ & 0.002 \\
\hline School building characteristics & 0.016 & 0.704 & 0.093 & 0.664 & $0.469 * *$ & 0.000 \\
\hline
\end{tabular}

Notes: aSpearman's correlation was used; ${ }^{* *}$ correlation is significant at 0.01 (two tailed). 
Table 5 Mean percent score of possible sources of lead exposure

\begin{tabular}{llll}
\hline & $<\mathbf{1 0} \boldsymbol{\mu g} / \mathbf{d L}$ & $\geq \mathbf{1 0} \boldsymbol{\mu g} / \mathbf{d L}$ & $\boldsymbol{P}_{\text {value }}$ \\
\hline Household exposure & $51.36 \pm 12.67$ & $54.69 \pm 12.67$ & 0.205 \\
School exposure & $66.94 \pm 6.60$ & $65.83 \pm 6.53$ & 0.420 \\
Family habits & $43.04 \pm 19.09$ & $75.83 \pm 22.06$ & $0.000^{*}$ \\
Personal habits & $55.56 \pm 17.74$ & $78.70 \pm 10.32$ & $0.000^{*}$ \\
Eating habits & $30.89 \pm 21.35$ & $72.22 \pm 30.56$ & $0.000^{*}$ \\
Total exposure score & $49.56 \pm 8.78$ & $69.46 \pm 8.69$ & $0.000^{*}$ \\
\hline
\end{tabular}

Notes: aP for $t$-test; ${ }^{*} P$ value significant below 0.05 .

$10 \mu \mathrm{g} / \mathrm{dL}$, and about the same number had concentrations of $>10 \mu \mathrm{g} / \mathrm{dL}$. Forty percent of all children had blood lead concentrations of $>5 \mu \mathrm{g} / \mathrm{dL}$ and half of these children had blood lead concentrations of $>10 \mu \mathrm{g} / \mathrm{dL}$; of these children, $97 \%$ were living in developing countries. The present work showed that $4.3 \%$ of students aged 6-18 years had BLLs $>10 \mu \mathrm{g} / \mathrm{dL}$, with a mean of $4.94 \pm 3.38 \mu \mathrm{g} / \mathrm{dL}$. This finding was less than expected and even approaches that of developed countries, indicating decreased exposure to different lead sources. Most of the parents and teachers from each school had a high degree of general hygiene - both at home and at school - despite the fact that they were unaware of the risks of lead poisoning and the possible degree of exposure to lead. ${ }^{2}$

According to the Centers for Disease Control and Prevention (CDC 1991), ${ }^{13}$ the definition of an elevated concentration of lead in the blood is $10 \mu \mathrm{g} / \mathrm{dL}$. However, evidence indicating that some health effects can occur below this threshold is accumulating. Recent analyses suggest that health effects may become apparent at concentrations of $<5 \mu \mathrm{g} / \mathrm{dL}$ and, indeed, that no evidence exists for a threshold, even at $1 \mu \mathrm{g} / \mathrm{dL} .^{14}$

Blood lead concentration is an indicator of recent lead exposure (within the preceding few weeks), rather than of cumulative long-term exposure. However, as exposure to lead varies relatively little over the span of 1 year, ${ }^{23}$ this measure can also be used to assess long-term exposure. ${ }^{22}$ This was consistent with this research finding where school construction characteristics, family $(P<0.0001)$, and personal and eating habits $(P<0.0001)$ were correlated with BLL.

A few studies reported small differences (typically $<10 \%$ ) between blood lead concentrations in males and females. ${ }^{23}$ This finding was true for this study, where there was a significant difference between males' and females' mean BLLs. Males were associated with elevated BLL, which may be due to behavioral differences between boys and girls. In the Second and Third National Health and Nutrition Examination Surveys, the prevalence of elevated BLL was higher among boys than in girls, but the difference was not statistically significant. ${ }^{24,25}$

Much research has been conducted recently on children with moderately raised BLLs associated with environmental exposure. The potential for adverse effects of lead exposure in children is heightened because: the intake of lead per unit body weight is higher for children than for adults; young children often place objects in their mouths, resulting in the possibility of dust and soil contaminated with lead being ingested; physiological uptake rates of lead in children are higher than those in adults; young children are undergoing rapid development; and their systems are not fully developed. ${ }^{26,27}$ Unlike overt lead toxicity, where there is usually one identifiable source, low-level environmental exposure to lead is associated with multiple sources (petrol, industrial processes, paint, solder in canned foods, water pipes) and pathways (air, household dust, street dirt, soil, water, food). ${ }^{17,28}$ In the current study, it was found that the possible sources for lead may be use of toothpaste, use of kohl, putting colored toys in the mouth, use of both canned food and juice, use of lip gloss in females, and different methods of handling newspaper while preparing

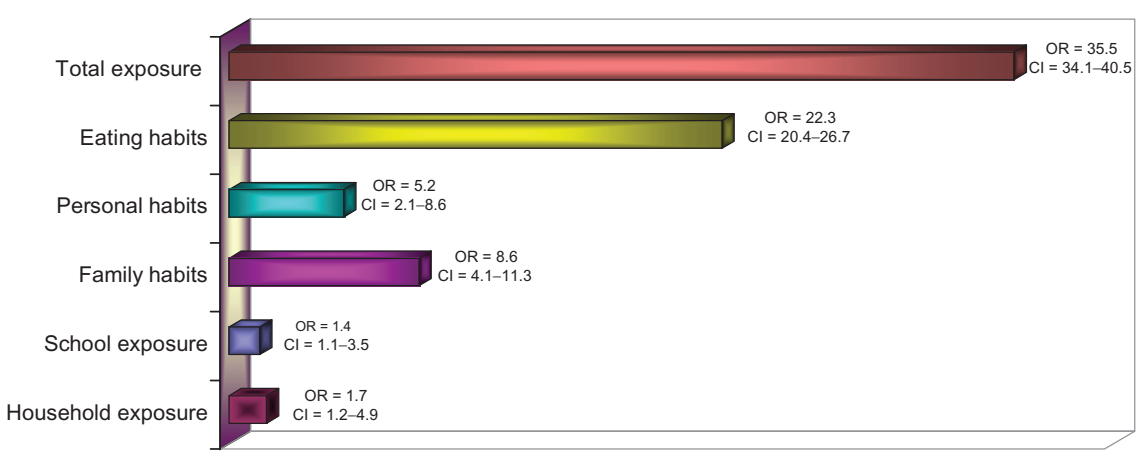

Figure 2 Association between BLL and scores of possible lead exposure (odds ratios [OR]).

Notes: Values are expressed as means \pm standard deviation or percentage scores. Odds ratios with $95 \%$ confidence intervals $(\mathrm{Cl})$ are reported for all variables entered into multivariate analysis $(P<0.05)$. 
Table 6 Relationship between blood lead level and hemoglobin level by age group

\begin{tabular}{|c|c|c|c|}
\hline & $<10 \mu \mathrm{g} / \mathrm{dL}$, mean $\pm \mathrm{SD}$ & $\geq 10 \mu \mathrm{g} / \mathrm{dL}$, mean $\pm \mathrm{SD}$ & $P$ value \\
\hline \multicolumn{4}{|l|}{$6 \leq 12$ years (both sexes) } \\
\hline All group $(\mathrm{N}=235)$ & $12.40 \pm 1.17$ & $9.33 \pm 0.94$ & $0.000 *$ \\
\hline Non-anemic group $(N=204)$ & $12.77 \pm 0.58$ & $10.66 \pm 0.68$ & $0.000 *$ \\
\hline${ }^{a} A n e m i c$ group $(N=3 \mathrm{I})$ & $10.09 \pm 1.28$ & $8.87 \pm 0.75$ & $0.000 *$ \\
\hline \multicolumn{4}{|l|}{$12 \leq 18$ years } \\
\hline \multicolumn{4}{|l|}{ Males } \\
\hline All group $(N=172)$ & $13.45 \pm 0.90$ & $10.55 \pm 1.27$ & $0.000 *$ \\
\hline Non-anemic group $(\mathrm{N}=129)$ & $13.85 \pm 0.49$ & $-* *$ & - \\
\hline${ }^{\mathrm{b}}$ Anemic group $(\mathrm{N}=43)$ & $12.13 \pm 0.67$ & $9.00 \pm 0.00 * * *$ & $0.000 *$ \\
\hline \multicolumn{4}{|l|}{ Females } \\
\hline All group $(\mathrm{N}=150)$ & $\mid 2.31 \pm 1.11$ & $10.42 \pm 1.26$ & $0.000 *$ \\
\hline Non-anemic group $(\mathrm{N}=103)$ & $|2.86 \pm 0.6|$ & $12.0 \pm 0.00 * * *$ & 0.165 \\
\hline 'Anemic group $(\mathrm{N}=47)$ & $10.26 \pm 1.21$ & $10.89 \pm 0.74$ & $0.04 I^{*}$ \\
\hline
\end{tabular}

Notes: ${ }^{* P}$ value for $t$-test significant below 0.05 ; **number $=0$; ***number $=1$; ${ }^{\text {anormal }}$ range for this age: $11.5-13.5 \mathrm{mg} / \mathrm{dL}$; ${ }^{b} \mathrm{normal}$ range for age and sex (male): I3-14.5 mg/dL; ' normal range for age and sex (females): $12-14 \mathrm{mg} / \mathrm{dL}$.

food - nearly the same sources found by other research as stated above.

This work indicated a significant relationship between BLL and hemoglobin level, especially among females $(P<0.0001)$ with lower mean hemoglobin level than males, and especially for age group 12-18 years. Hazards for anemia and gastrointestinal effects were based on a large review of toxicological and epidemiological data. ${ }^{27}$ Based on the results of a study by Schwartz, et al, ${ }^{29}$ as a consequence of individual variation, we considered that only $20 \%$ of the people with blood lead concentrations above those indicated by the Agency for Toxic Substances and Disease Registry would actually develop symptoms. ${ }^{29,30}$ Absorbed lead inhibits the activity of a number of enzymes involved in heme biosynthesis. Several studies have shown that the activity of $\delta$-aminolevulinic acid dehydratase is affected at very low BLLs, with no apparent threshold. ${ }^{31}$ Typically, lead-induced anemia arises from a combination of reduced hemoglobin formation (caused either by impaired heme synthesis or globin chain formation) and reduction in erythrocyte survival because of hemolysis. $^{32}$

\section{Conclusion}

Female students have a higher blood lead level than males. They also have a lower blood hemoglobin level. The possible sources of lead exposure included the use of toothpaste, kohl, canned food and canned juice, putting colored toys in the mouth, use of lip gloss in females, and different methods of handling newspaper while preparing food.

\section{Recommendation}

A health-education intervention program should be planned and directed to parents, teachers, and students to increase their awareness of sources of lead exposure and how to avoid

Table 7 Predictors of high blood lead level among schoolchildren

\begin{tabular}{|c|c|c|c|c|c|}
\hline & B & $\beta$ & $t$ & Significance & $95 \%$ of $\mathrm{Cl}$ for $\mathrm{B} * *$ \\
\hline Use of bakhoor ${ }^{a}$ & 0.006 & 0.012 & 0.309 & 0.757 & -0.034 to 0.046 \\
\hline Use of toothpaste & 0.074 & 0.151 & 3.710 & $0.000 *$ & $0.035-0.113$ \\
\hline Use of kohlb & 0.080 & 0.194 & 4.671 & $0.000 *$ & $0.046-0.114$ \\
\hline Passive smoking & 0.027 & 0.065 & 1.693 & 0.091 & -0.004 to 0.57 \\
\hline Putting colored toys in mouth & 0.057 & 0.140 & 3.613 & $0.000 *$ & $0.026-0.088$ \\
\hline Use of canned food & 0.051 & 0.113 & 2.674 & $0.008^{*}$ & $0.014-0.088$ \\
\hline Use of canned juice & 0.056 & 0.101 & 2.366 & $0.018^{*}$ & $0.010-0.102$ \\
\hline Use of cosmetics & 0.019 & 0.039 & 0.720 & 0.472 & $0.071-0.033$ \\
\hline Use of lip gloss & 0.118 & 0.270 & 4.587 & $0.000 *$ & $0.067-0.168$ \\
\hline \multicolumn{6}{|l|}{ Use of newspapers } \\
\hline Food preparation & 0.062 & 0.146 & 3.509 & $0.000 *$ & $0.027-0.097$ \\
\hline Table mats & 0.130 & 0.312 & 6.999 & $0.000 *$ & $0.093-0.166$ \\
\hline Wrapping & 0.960 & 0.200 & 4.940 & $0.000 *$ & $0.058-0.134$ \\
\hline Use of colored pencils & 0.027 & 0.054 & 1.400 & 0.162 & $-0.01 \mathrm{I}-0.065$ \\
\hline
\end{tabular}

Notes: *Significance below level of 0.05 ; **Confidence interval $(\mathrm{Cl})$. "“"Bakhoor," from the Arabic language, is today used to describe most incense resins or fragranced wood chips. ${ }^{b} \mathrm{Kohl}$ is an ancient eye cosmetic. 
them. Possible interventions include providing soap and water at schools and homes, frequently washing hands and face, thoroughly cleaning fruits and vegetables, and limiting dust on floors and furniture. Children should be educated not to suck on their fingers, pencils, or toys, or to eat soil. A treatment plan should be designed for those who have an elevated BLL, with continuous evaluation.

\section{Study limitation}

An assessment of the effect of BLL upon scholastic achievement together with measurement of the intelligence quotient for both students and their parents (especially mother) were needed, but many difficulties (related to schools, students, and parents) faced the authors in carrying these out.

\section{Acknowledgments}

This research work was financially supported by research grant 440/430, funded by the Deanship of Scientific Research, Taibah University, Al-Madinah Al-Munawwarah, Saudi Arabia. The authors also thank the Ministry of Education for approving the study protocol, the local field workers for their invaluable assistance in the data collection activities, and the school principals and teachers for welcoming us into their schools.

\section{Disclosure}

The authors report no conflicts of interest in this work.

\section{References}

1. Needleman H. Lead poisoning. Annu Rev Med. 2004;55:209-222.

2. Meyer PA, Brown MJ, Falk H. Global approach to reducing lead exposure and poisoning. Mutat Res. 2008;659(1-2):166-175.

3. Toscano CD, Guilarte TR. Lead neurotoxicity: from exposure to molecular effects. Brain Res Rev. 2005;49(3):529-554.

4. Garza A, Vega R, Soto E. Cellular mechanisms of lead neurotoxicity. Med Sci Monit. 2006;12(3):RA57-RA65.

5. Gottesfeld P, Pokhrel AK. Review: lead exposure in battery manufacturing and recycling in developing countries and among children in nearby communities. J Occup Environ Hyg. 2011;8(9):520-532.

6. Brown MJ, Raymond J, Homa D, Kennedy C, Sinks T. Association between children's blood lead levels, lead service lines, and water disinfection, Washington, DC, 1998-2006. Environ Res. 2011;111(1):67-74.

7. Lin SH, Wang XR, Yu IT, Tang WN, Li J, Liu BO. Lead powder use for skin care and elevated blood lead level among children in a Chinese rural area. J Expo Sci Environ Epidemiol. 2011;22(2):198-203.

8. Kauffman JF, Westenberger BJ, Robertson JD, Guthrie J, Jacobs A, Cummins SK. Lead in pharmaceutical products and dietary supplements. Regul Toxicol Pharmacol. 2007;48(2):128-134.

9. Rappazzo K, Cummings CE, Himmelsbach RM, Tobin R. The effect of housing compliance status on children's blood lead levels. Arch Environ Occup Health. 2007;62(2):81-85.

10. Jakubowski M. Low-level environmental lead exposure and intellectual impairment in children - the current concepts of risk assessment. Int $J$ Occup Med Environ Health. 2011;24(1):1-7.

11. Markowitz M. Lead poisoning. Pediatr Rev. 2000;21:327-335.
12. Iglesias V, Steenland K, Maisonet M, Pino P. Exposure to lead from a storage site associated with intellectual impairment in Chilean children living nearby. Int J Occup Environ Health. 2011;17(4): 314-321.

13. Centers for Disease Control and Prevention (CDC). Preventing Lead Poisoning in Young Children: A Statement by the Centers for Disease Control. Atlanta, GA: CDC; 1991.

14. Lanphear BP, Dietrich P, Auinger P, Cox C. Subclinical lead toxicity in US children and adolescents. Public Health Rep. 2000;115: $521-529$.

15. Schwartz J. Low-level lead exposure and children's IQ: a meta-analysis and search for a threshold. Environ Res. 1994;65:42-55.

16. World Health Organization (WHO). The WHO World Health Report 2001. Geneva: World Health Organization; 2001.

17. Von Schirnding YE. The impact of lead poisoning on the workforce and society. In: George AM, editor. Proceedings of the International Conference on Lead Poisoning; 1999 February 8-10; Bangalore, India. Bangalore: The George Foundation; 1999: 41-47.

18. Lwanga SK, Lemeshow S. Sample Size Determination in Health Studies: A Practical Manual. Geneva: WHO; 1991.

19. Hu H, Aro A, Payton M, et al. The relation of bone and blood lead to hypertension. JAMA. 1996; 275(15):1171-6.

20. Peng S, Zhang $C$, Wang $C$, et al. The investigation on the changes of hematological parameters in the occupationally lead exposed workers. Zhonghau Lao Dong Wei Sheng Zhi Ye Bing Za Zhi. 2002;20(5): 334-5.

21. Brody DJ, Pirkle JL, Kramer RA, et al. Blood lead levels in the U.S. population: phase 1 of the Third National Health and Nutrition Examination Survey (NHANES III, 1988 to 1991). JAMA. 1994; 272(4):277-283.

22. Rubin $\mathrm{CH}$, Esteban E, Jones R, et al. Childhood lead poisoning in Russia: a site-specific pediatric blood lead evaluation. Int $J$ Occup Environ Health. 1997;3(4):241-248.

23. WHO. Air Management Information System (AMIS) 2.0. Geneva: WHO; 1998.

24. Mahaffey KR, Annest JK, Roberts J, Murphy RS. National estimates of blood lead levels: United States, 1976-1980: association with selected demographic and socioeconomic factors. $N$ Engl $J$ Med. 1982;307:573-579.

25. Pirkle JL, Kaufmann RB, Brody DJ, Hickman T, Gunter EW, Paschal DC. Exposure of the U.S. population to lead, 1991-1994. Environ Health Perspect. 1998;106:745-750

26. Nriagu J, Senthamarai-Kannan R, Jamil H, Fakhori M, Korponic S. Lead poisoning among Arab American and African American children in the Detroit metropolitan area, Michigan. Bull Environ Contam Toxicol. 2011;87(3):238-244.

27. Tong S, McMichael AJ. The magnitude, persistence and public health significance of cognitive effects of environmental lead exposure in childhood. J Environ Med. 1999;1(2):103-110.

28. Maas RP, Patch SC. Update on research findings and regulatory/legal activities regarding tap water lead exposure from traditional leadedbrass and "no-lead" type plumbing parts. J New Engl Water Works Assn. 2004;86:114-127.

29. Schwartz J, Landrigan PJ, Baker EL Jr, Orenstein WA, von Lindern IH. Lead-induced anemia: dose-response relationships and evidence for a threshold. American Journal of Public Health. 1990;80(2): $165-168$.

30. Agency for Toxic Substances and Disease Registry. Toxicological Profile for Lead (Update). Atlanta, GA: US Department of Health and Human Services; 1999.

31. Scinicariello F, Murray HE, Moffett DB, Abadin HG, Sexton MJ, Fowler BA. Lead and delta-aminolevulinic acid dehydratase polymorphism: where does it lead? A meta-analysis. Environ Health Perspect. 2007;115(1):35-41.

32. Wang Q, Zhao HH, Chen JW, et al. delta-Aminolevulinic acid dehydratase activity, urinary delta-aminolevulinic acid concentration and zinc protoporphyrin level among people with low level of lead exposure. Int J Hyg Environ Health. 2010;213(1):52-58. 
International Journal of General Medicine

Dovepress

\section{Publish your work in this journal}

The International Journal of General Medicine is an international, peer-reviewed open-access journal that focuses on general and internal medicine, pathogenesis, epidemiology, diagnosis, monitoring and treatment protocols. The journal is characterized by the rapid reporting of reviews, original research and clinical studies across all disease areas.

A key focus is the elucidation of disease processes and management protocols resulting in improved outcomes for the patient. The manuscript management system is completely online and includes a very quick and fair peer-review system. Visit http://www.dovepress.com/ testimonials.php to read real quotes from published authors.

Submit your manuscript here: http://www.dovepress.com/international-journal-of-general-medicine-journal 